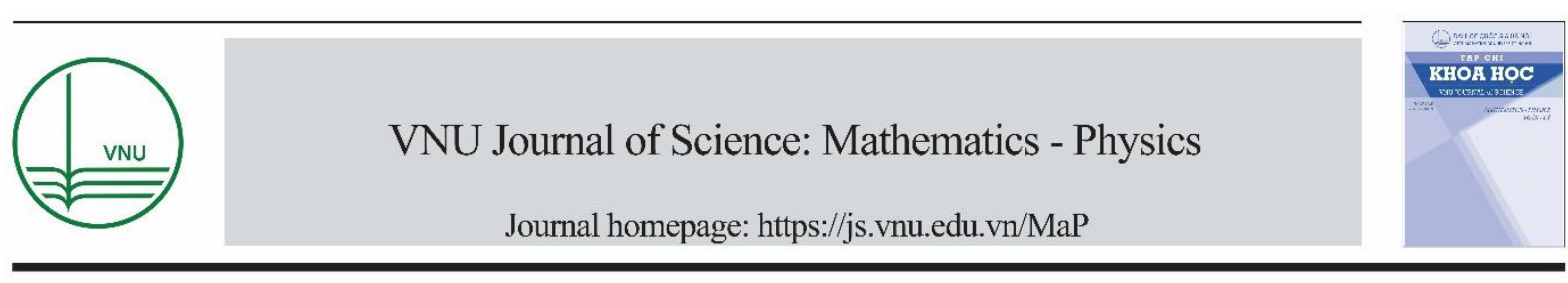

Original Article

\title{
Fabrication of Organic Solar Cell Utilizing Mixture of Solution-processable Phthalocyanine and Fullerene Derivative with Processing Additive Solvent
}

\author{
Quang-Duy Dao* \\ Faculty of Physics, VNU University of Science, 334 Nguyen Trai,Thanh Xuan, Hanoi, Vietnam \\ Received 08 October 2019 \\ Revised 26 November 2019; Accepted 03 December 2019

\begin{abstract}
We demonstrate an efficient bulk heterojunction (BHJ) organic solar cell (OSCs) utilizing a soluble phthalocyanine derivative, 1,4,8,11,15,18,22,25-octahexylphthalocyanine $\left(\mathrm{C}^{2} \mathrm{PcH}_{2}\right)$, and a fullerene derivative, 1-(3-methoxy-carbonyl)-propyl-1-1-phenyl-(6,6)C71 and roles of processing additive solvent on improvement of the BHJ OSCs. By adding processing additive solvent, filling factor and short-circuit current density are improved to 0.57 and $8.6 \mathrm{~mA} / \mathrm{cm}^{2}$, respectively. As a result, the power conversion efficiency of $3.6 \%$ is achieved. Otherwise, the effects of processing additive solvent are demonstrated by taking the absorption and photoluminescence spectra of $\mathrm{C}_{6} \mathrm{PcH}_{2}$ and composite thin films into account.
\end{abstract}

Keywords: Phthalocyanine, organic solar cells, thin film, small molecule, processing additive.

\section{Introduction}

Organic solar cells (OSCs) utilizing solution-processable small-molecule (SM) donors mixed with fullerene derivative have considered as an alternative to OSCs based on the conventional conjugated polymers [1-6]. Comparing with polymer-based donors, SM-based donors expose the dominant characteristics, such as relatively high charge carrier mobility, well-defined structures without end group contaminants, and simple synthesis and purification. OSCs based on SM donors in both of conventional and inverted structures have exhibited the relatively high photovoltaic performance with the power conversion efficiencies (PCEs) exceeding 10\% [1].

\footnotetext{
${ }^{*}$ Corresponding author.

Email address: daoquangduy@hus.edu.vn
}

https//doi.org/ 10.25073/2588-1124/vnumap.4402 
Discotic liquid crystalline (DLC) materials have been reported as potential SM donors in bulk heterojunction (BHJ) OSC field [7-9]. DLC materials exhibit the appealing characteristics, such as the strong optical absorption at visible-light ranges, the large exciton diffusion length, and the relatively high charge carrier mobility [8]. Furthermore, the high solubility in conventional organic solvents and the strong self-organizing nature which leads to relatively easy fabrication of high quality thin films with large areas of mono-domain have made DLC materials more suitable for BHJ OSC application [10-14]. In this study, we demonstrate the relatively high photovoltaic performance OSCs utilizing nonperipherally substituted octahexyl phthalocyanine $\left(\mathrm{C} \mathrm{PcH}_{2}\right)$ (Fig. 1(a)) $\mathrm{SM}$ donor mixed with a fullerene derivative, 1-(3-methoxy-carbonyl)-propyl-1-1-phenyl-(6,6)C71 $\left(\mathrm{PC}_{70} \mathrm{BM}\right)$ and the effects of processing additive on the device photovoltaic performance.

\section{Experimental Procedure}

\subsection{Sample and device fabrication}

BHJ OSCs, which had the device architecture as shown in Fig. 1(b), were prepared under optimized conditions in accordance with the previous literature [10]. In particular, indium tin oxide (ITO)-coated glass was patterned by wet-etching method using hydrochloric acid at $40^{\circ} \mathrm{C}$. The patterned ITO-coated glasses were then cleaned with detergent, water, chloroform, acetone, and isopropyl alcohol. In sequence, the ITO substrates were treated with UV-induced ozone to remove the redundant organic solvents. After that, $\mathrm{MoO}_{\mathrm{x}}$ films were thermally evaporated onto the patterned-ITO substrates at a rate of $0.1 \AA / \mathrm{s}$ under a vacuum of about $2 \times 10^{-5} \mathrm{~Pa}$. The thickness of $\mathrm{MoO}_{\mathrm{x}}$ film was around $6 \mathrm{~nm}$. A solution containing a mixture of $\mathrm{C}_{6} \mathrm{PcH}_{2}$ and $\mathrm{PC}_{70} \mathrm{BM}(2: 1)$ in chloroform at a total solids concentration of 22.35 $\mathrm{mg} / \mathrm{ml}$ was then spin coated on the top of $\mathrm{MoO}_{\mathrm{x}}$ layers in a $\mathrm{N}_{2}$-filled glove box. The thickness of $\mathrm{C} \mathrm{PcH}_{2}$ and $\mathrm{PC}_{70} \mathrm{BM} \mathrm{BHJ}$ layer was around $150 \mathrm{~nm}$. To improve the nano-scale phase separation of donor and acceptor as well the photovoltaic performance of $\mathrm{C} \mathrm{PcH}_{2}$-based devices, various amount of 1,8diiodooctane (DIO, as shown in Fig. 1(b)) was added as a processing additive solvent [11]. Finally, 80nm-thick aluminum and 3-nm-thick LiF films were thermally deposited at a rate of 3 and $0.1 \AA$ s under a vacuum of about $2 \times 10^{-5} \mathrm{~Pa}$, respectively. The device area was $4 \mathrm{~mm}^{2}$.

(a)
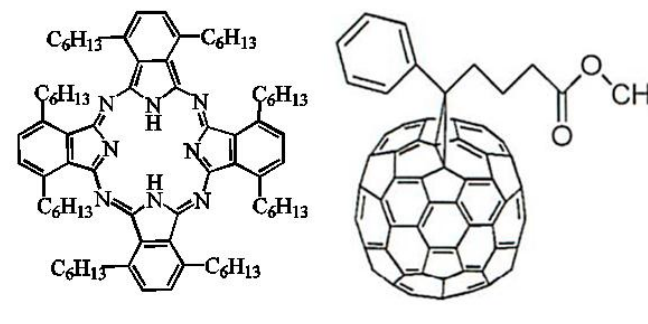

$\mathrm{C6PcH}_{2}$

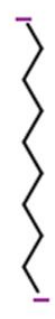

DIO (b)

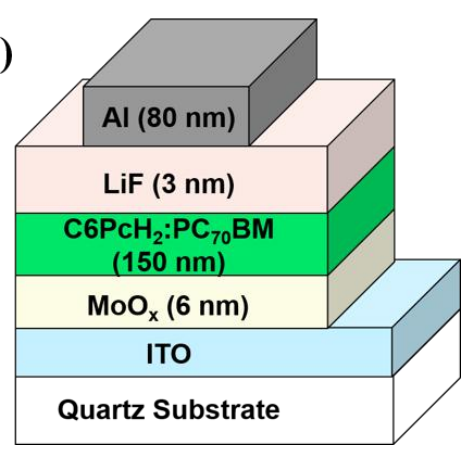

Figure 1. (a) Chemical structure of materials and (b) device architecture in this study.

$\mathrm{C}_{6} \mathrm{PcH}_{2}$ was synthesized in accordance with the literature with slight modifications as following procedures $[8,15]$. In particular, $\mathrm{C} \mathrm{PcH}_{2} \mathrm{SM}$ was fully purified by column chromatography (silica gel with toluene as the eluent) and repeatedly recrystallized from toluene-methanol (3:1) solution. $\mathrm{PC}_{70} \mathrm{BM}$ (Frontier carbon Ltd.) and DIO (Sigma Aldrich) was used without further purification. 


\subsection{Film and device characterization}

The current density-voltage $(J-V)$ characteristics were measured using a source measurement unit (Keithley 2400) under 1-sun condition (using an XES 301 (AM $1.5 \mathrm{G}$ ) full spectrum solar simulator with the irradiation intensity of $100 \mathrm{~mW} / \mathrm{cm}^{2}$ ). The external quantum efficiency (EQE) spectra were measured using a xenon lamp light passing through a mono-chromator as a light source. The measurement system was calibrated using Si reference cells. The measured $J-V$ characteristics show good agreements with the integrated EQE values. While the active-layer thickness was directly measured using atomic force microscopy (AFM, Keyence VN-8000), the thickness of $\mathrm{LiF}$ and $\mathrm{MoO}_{\mathrm{x}}$ thin films was measured using thickness sensor, which inserted in vacuum chamber of with thermal evaporation system. We note that the thickness sensor in this study has been calibrated using AFM. The absorption and photoluminescence (PL) spectra of the $\mathrm{C}^{2} \mathrm{PcH}_{2}: \mathrm{PC}_{70} \mathrm{BM} \mathrm{BHJ}$ thin films were measured by spectrophotometry (Shimadzu UV-3150) and fluorescence spectrophotometer (Hitachi F-4500), respectively.

\section{Results and discussion}

Figure 2 shows the normalized absorption spectra of $\mathrm{C}_{6 \mathrm{PcH}}, \mathrm{PC}_{70} \mathrm{BM}$, and $\mathrm{C}_{6} \mathrm{PcH}_{2}: \mathrm{PC}_{70} \mathrm{BM}$ composites in solid thin films, fabricated on glass substrates. The absorption spectra of the $\mathrm{C}^{2} \mathrm{PcH}_{2} \mathrm{SM}$ donor exhibited the strong peaks at around 408 and $700 \mathrm{~nm}$, related to allowed B transition and forbidden $\mathrm{Q}$ transition of porphyrinoid complexes, respectively [16, 17]. However, the absorption intensity at around $500 \mathrm{~nm}$ was quite low. By mixing $\mathrm{C}_{6} \mathrm{PcH}_{2} \mathrm{SM}$ donor with $\mathrm{PC}_{70} \mathrm{BM}$ acceptor, the absorption intensity at round $500 \mathrm{~nm}$ was improved due to the absorption of $\mathrm{PC}_{70} \mathrm{BM}$ molecules. As a result, the absorption of $\mathrm{C}_{6} \mathrm{PcH}_{2}: \mathrm{PC}_{70} \mathrm{BM}$ composite thin film covered all visible spectral range.

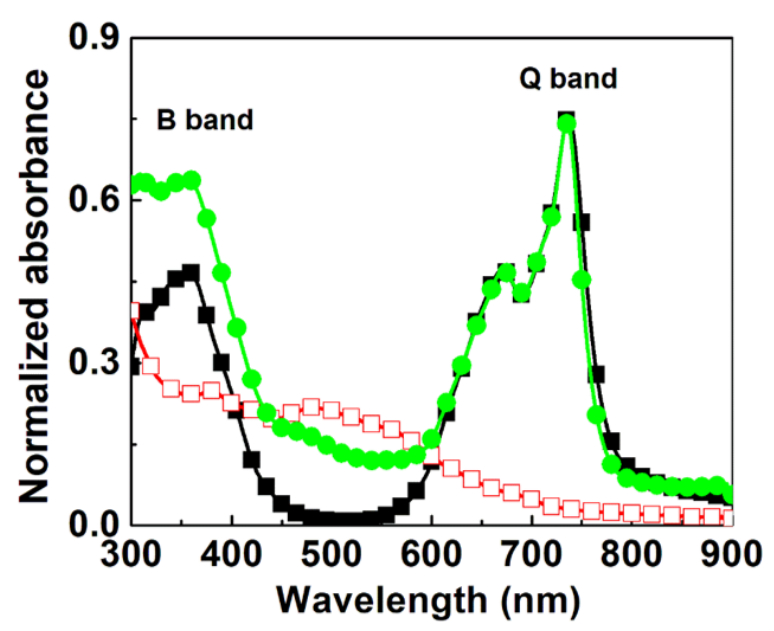

Figure 2. Absorption spectra of $\mathrm{C}_{6} \mathrm{PcH}_{2}$ (filled-rectangles), $\mathrm{PC}_{70} \mathrm{BM}$ (empty-rectangles), and $\mathrm{C}_{6} \mathrm{PcH}_{2}: \mathrm{PC}_{70} \mathrm{BM}$ composite (filled-circles) thin films.

Figures 3(a) shows the EQE spectra of the BHJ OSCs on glass substrates utilizing $\mathrm{C} \mathrm{PcH}_{2} \mathrm{SM}$ donor mixed with $\mathrm{PC}_{70} \mathrm{BM}$ acceptor with various amount of DIO processing additive solvent. The devices utilizing $\mathrm{C}_{6} \mathrm{PcH}_{2}: \mathrm{PC}_{70} \mathrm{BM}$ composite thin films without DIO processing additive solvent exhibited broad EQE curves throughout the visible region, with the three predominated peaks at around 700, 400 and $500 \mathrm{~nm}$. The shape of EQE curve was good agreement with the aforementioned absorption spectra 
of the $\mathrm{C}_{6} \mathrm{PcH}_{2}: \mathrm{PC}_{70} \mathrm{BM}$ composite thin films. However, the EQE was relatively poor with the intensity of $8 \%$ at $700 \mathrm{~nm}$ due to the poor nano-scale donor-acceptor separation in the composite thin films [11]. By adding DIO processing additive solvent, the EQE of the OSC utilizing $\mathrm{C} \mathrm{PcH}_{2}: \mathrm{PC}_{70} \mathrm{BM}$ composite thin film was markedly improved. Particularly, the EQE intensity at $730 \mathrm{~nm}$ was improved to $43 \%$ by adding $0.2 \% \mathrm{v} / \mathrm{v}$ of DIO processing additive solvent. We suggested that by adding the processing additive solvent, the nano-scale donor-acceptor phase separation of the $\mathrm{C}_{6} \mathrm{PcH}_{2}: \mathrm{PC}_{70} \mathrm{BM}$ composite thin film was improved, which caused the improvement in the device photovoltaic performance. However, the $\mathrm{EQE}$ intensity of the fabricated devices was reduced by adding $0.3 \% \mathrm{v} / \mathrm{v}$ of DIO processing additive solvent.

Figure 3(b) shows the $J$ - $V$ characteristics of BHJ OSCs on glass substrates utilizing $\mathrm{C}^{2} \mathrm{PcH}_{2} \mathrm{SM}$ donors mixed with $\mathrm{PC}_{70} \mathrm{BM}$ acceptors with various amount of the DIO processing additive solvent, under AM $1.5 \mathrm{G}$ illumination at an intensity of $100 \mathrm{~mW} / \mathrm{cm}^{2}$. The all device data are summarized in Table 1. The devices based the $\mathrm{C} \mathrm{PcH}_{2} \mathrm{SM}$ donor without the DIO processing additive solvent exhibited the relatively poor $J-V$ characteristics with the short-circuit current density $\left(J_{s c}\right)$ of $1.6 \mathrm{~mA} / \mathrm{cm}^{2}$ and the open-circuit voltage $\left(V_{o c}\right)$ of $0.81 \mathrm{~V}$. With the filling factor $(F F)$ of 0.27 , the PCEs of $0.4 \%$ were achieved. By using DIO processing additive solvent, the photovoltaic performance of the BHJ OSC was markedly improved. In particular, the $J_{s c}$ and $F F$ of the fabricated devices were improved to $8.6 \mathrm{~mA} / \mathrm{cm}^{2}$ and 0.57 , respectively. As a result, the PCE of $3.6 \%$ was achieved. Although the PCE of BHJ OSC utilizing $\mathrm{C}_{6} \mathrm{PcH}_{2}$ mixed with $\mathrm{PC}_{70} \mathrm{BM}$ was still relatively low comparing with those of $\mathrm{BHJ}$ OSC utilizing benzodithiophene SM due to the low highest occupied molecular orbital energy levels of $\mathrm{C} \mathrm{PcH}_{2} \mathrm{SM}$ and/or the simple architecture of cell in this study, those results indicated that $\mathrm{C} \mathrm{PcH}_{2} \mathrm{SM}$ could be a potential donor in BHJ OSC [1]. On the other hand, the PCE of the fabricated devices was reduced to $1.8 \%$ when $0.3 \% \mathrm{v} / \mathrm{v}$ DIO was added to the mixture of $\mathrm{C}_{6} \mathrm{PcH}_{2}: \mathrm{PC}_{70} \mathrm{BM}$ solution. Those results were quite good agreement with the aforementioned $\mathrm{EQE}$ spectra of the device utilizing the $\mathrm{C}_{6} \mathrm{PcH}_{2}: \mathrm{PC}_{70} \mathrm{BM}$ composite thin films.

The PL spectra of $\mathrm{C}_{6} \mathrm{PcH}_{2}$ and $\mathrm{C}_{6} \mathrm{PcH}_{2}: \mathrm{PC}_{70} \mathrm{BM}$ thin films fabricated on glass substrates with various DIO processing-additive solvent are shown in Fig. 4. The PL spectra of $\mathrm{C}^{2} \mathrm{PcH}_{2}$ thin films had a shoulder at around $820 \mathrm{~nm}$ and a strong peak at $766 \mathrm{~nm}$, related to the Q-band of the $\mathrm{C} \mathrm{PcH}_{2}$ absorption spectra. The PL intensity of the $\mathrm{C}_{6} \mathrm{PcH}_{2} \mathrm{SM}$ donors was markedly suppressed by adding the $\mathrm{PC}_{70} \mathrm{BM}$ acceptors. Those results indicated that the photo-induced electrons transfer from the excited state of $\mathrm{C}_{6 \mathrm{PcH}}$ to $\mathrm{PC}_{70} \mathrm{BM}$ [18-20]. However, the PL intensity of $\mathrm{C}_{6 \mathrm{PcH}}: \mathrm{PC}_{70} \mathrm{BM}$ thin films was increased by adding DIO processing-additive solvent. The increases in the PL intensity indicated that the interfacial areas between the donor and acceptor were enlarged or the nano-scale donor-acceptor phase separation was improved by adding DIO processing additive solvent, which was in good agreement with the aforementioned increases in the $J_{s c}$ and PCE of the fabricated devices [11,13,14].

Table 1. OSCs utilizing $\mathrm{C}_{6} \mathrm{PcH}_{2}: \mathrm{PC}_{70} \mathrm{BM} \mathrm{BHJ}$ thin film with various amounts of DIO processing additive solvent

\begin{tabular}{lllll}
\hline $\begin{array}{l}\text { Amount of } \\
\text { DIO }(\% \mathrm{v} / \mathrm{v})\end{array}$ & $V_{o c}(\mathrm{~V})$ & $\begin{array}{l}J_{s c} \\
\left(\mathrm{~mA} / \mathrm{cm}^{2}\right)\end{array}$ & $F F(\%)$ & PCE $(\%)$ \\
\hline 0 & 0.81 & 1.6 & 0.27 & 0.4 \\
0.1 & 0.77 & 7.0 & 0.38 & 2.1 \\
0.2 & 0.74 & 8.6 & 0.57 & 3.6 \\
0.25 & 0.73 & 8.3 & 0.53 & 3.2 \\
0.3 & 0.74 & 5.5 & 0.44 & 1.8 \\
\hline
\end{tabular}



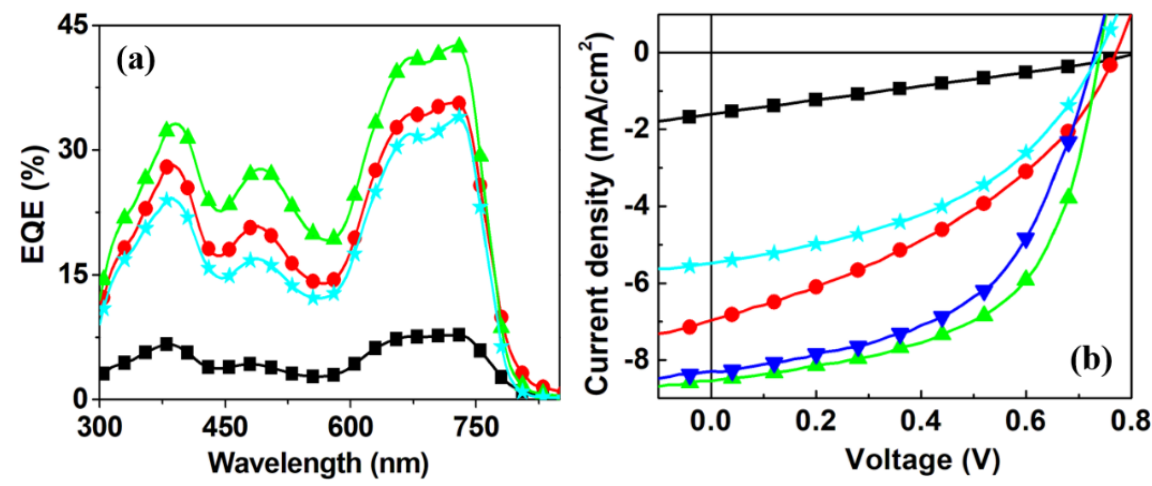

Figure 3. (a) EQE spectra and (b) $J-V$ characteristics of OSCs utilizing $\mathrm{C}_{6} \mathrm{PcH}_{2}: \mathrm{PC}_{70} \mathrm{BM} \mathrm{BHJ}$ thin film with various amounts of DIO processing additive solvent: 0 (rectangles), 0.1 (circles), 0.2 (up-triangles),

0.25 (down-triangles), and 3 (stars) \%v/v.

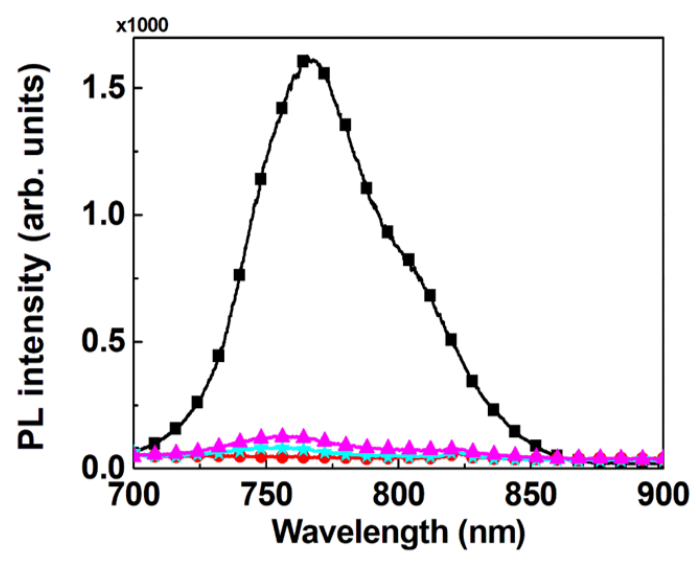

Figure 4. PL spectra of $\mathrm{C} 6 \mathrm{PcH}_{2}$ (rectangles) and $\mathrm{C} \mathrm{PcH}_{2}: \mathrm{PC}_{70} \mathrm{BM} \mathrm{BHJ}$ thin film with various amounts of DIO processing additive solvent: 0 (circles), 0.25 (stars), and 3 (up-triangles) \%v/v.

Figure 5(a) shows the absorption spectra at the $\mathrm{Q}$ band of the $\mathrm{C} 6 \mathrm{PcH}_{2}$ and $\mathrm{C}_{6 \mathrm{PcH}}: \mathrm{PC}_{70} \mathrm{BM}$ composite in solution and solid thin films. It indicated that the width of the $\mathrm{Q}$ band was changed by adding $\mathrm{PC}_{70} \mathrm{BM}$ and/or DIO processing additive solvent. Figure 5(b) shows the the Davydov splitting at the $\mathrm{Q}$ band or the width of $\mathrm{Q}$ band of the $\mathrm{C} \mathrm{PcH}_{2}$ and $\mathrm{C}_{6} \mathrm{PcH}_{2}: \mathrm{PC}_{70} \mathrm{BM}$ composite in solution and solid thin films. We note that the width of the Davydov splitting at $\mathrm{Q}$ band of phthalocyanine molecules is related to the interaction energy between discotic $\mathrm{C} 6 \mathrm{PcH}_{2}$ with different site symmetries. In particular, the increases in the Davydov splitting at Q band suggest that the molecular interaction of $\mathrm{C}^{2} \mathrm{PcH}_{2}$ molecules was reinforced. As shown in Fig. 5(b), the Davydov splitting at $\mathrm{Q}$ band increased and molecular interaction of $\mathrm{C} \mathrm{PcH}_{2}$ molecules was reinforced after removing the solvent. On the other hand, the Davydov splitting at $\mathrm{Q}$ band decreased by adding $\mathrm{PC}_{70} \mathrm{BM}$ acceptor. Those results suggest that the dispersion of $\mathrm{PC}_{70} \mathrm{BM}$ molecules into the $\mathrm{C}_{6 \mathrm{PcH}}$ domains was occurred and weakened the molecular interaction of discotic $\mathrm{C} \mathrm{PcH}_{2}$. However, by adding the DIO processing additive solvent, the Davydov splitting at $\mathrm{Q}$ band increased again. We suggest that the doping DIO processing additive solvent separated the phase of $\mathrm{C} \mathrm{PcH}_{2}$ donors and $\mathrm{PC}_{70} \mathrm{BM}$ acceptors, which was in good agreement with the aforementioned improvement of the $\mathrm{BHJ}$ OSCs utilizing the $\mathrm{C} \mathrm{PcH}_{2}: \mathrm{PC}_{70} \mathrm{BM}$ composites thin films $[11,13,14]$. 

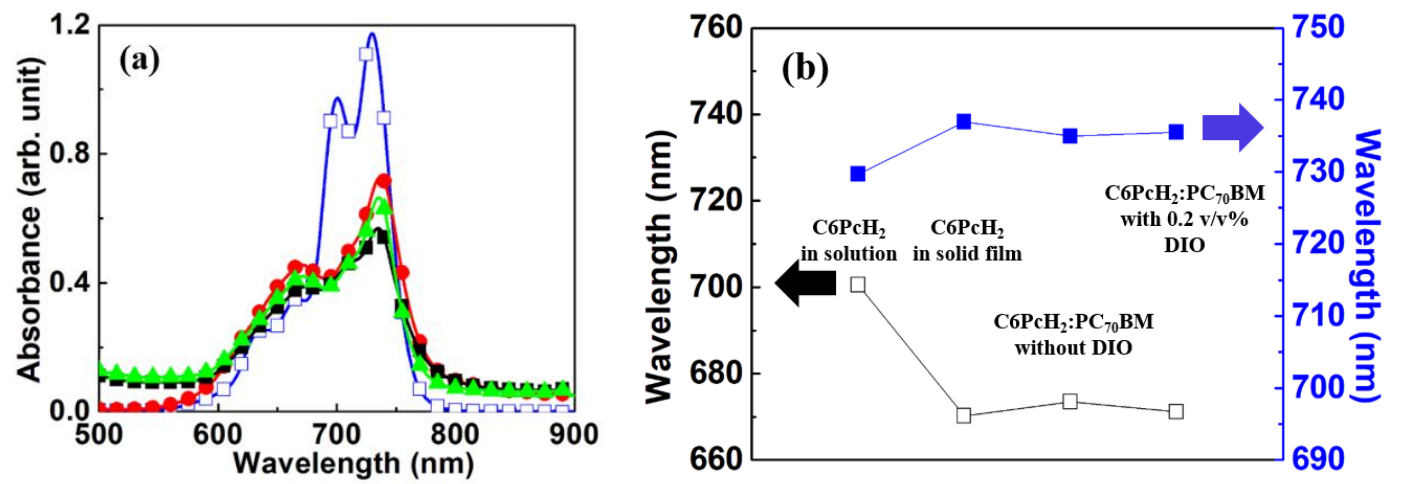

Figure 5. (a) Absorption spectra $\mathrm{C} \mathrm{PcH}_{2}$ in chloroform solution (empty-rectangles) and solid thin films (filledcircles) and absorption spectra of $\mathrm{C} \mathrm{PcH}_{2}: \mathrm{PC}_{70} \mathrm{BM} \mathrm{BHJ}$ thin film with various amounts of DIO processing additive solvent: 0 (filled-rectangles) and 2 (up-triangles) \%v/v and (b) dependence of size of the Davydov splitting of $\mathrm{C}_{6 \mathrm{PcH}}$ and $\mathrm{C} 6 \mathrm{PcH}_{2}: \mathrm{PC}_{70} \mathrm{BM} \mathrm{BHJ}$ thin film.

\section{Conclusions}

In summary, an efficient BHJ OSC in ITO/MoO $/ \mathrm{C} 6 \mathrm{PcH}_{2}: \mathrm{PC}_{70} \mathrm{BM} / \mathrm{Al}$ structure was fabricated with the relatively high photovoltaic performance. Furthermore, the roles of the DIO processing additive solvent on the photovoltaic performance of $\mathrm{BHJ}$ OSCs utilizing $\mathrm{C} 6 \mathrm{PcH}_{2}: \mathrm{PC}_{70} \mathrm{BM}$ composite thin films was taken into account. Particularly, by adding $0.2 \% \mathrm{v} / \mathrm{v}$ of DIO processing additive solvent, the nanoscale donor-acceptor phase separation was improved and the EQE at the Q band of BHJ OSC utilizing $\mathrm{C} \mathrm{PcH}_{2}: \mathrm{PC}_{70} \mathrm{BM}$ composite thin films increased from 8 to $43 \%$. Hence, the $J_{s c}$ and $F F$ were markedly improved to $8.6 \mathrm{~mA} / \mathrm{cm}^{2}$ and 0.57 , respectively. Finally, the PCE of $3.6 \%$ was achieved.

\section{Acknowledgments}

This research is funded by Vietnam National Foundation for Science and Technology Development (NAFOSTED) under grant number 103.02-2018.320. Author also thanks Prof. Akihiko Fujii (Osaka University), Prof. Masanori Ozaki (Osaka University), and Dr. Yo Shimizu (National Institute of Advanced Industrial Science and Technology) for material and equipment supports.

\section{References}

[1] R. Ilmi, A. Haque, M.S. Khan, High efficiency small molecule-based donor materials for organic solar cells, Org. Electron. 58 (2018) 53-62.

[2] L. Schmidt-Mende, A. Fechtenkotter, K. Mullen, E. Moons, RH. Friend, J.D. MacKenzie, Self-organized discotic liquid crystals for high-efficiency organic photovoltaics, Science 293 (2001) 1119-1122.

[3] Y. Wang, M. Chang, B. Kan, X. Wan, C. Li, Y. Chen, All-Small-Molecule Organic Solar Cells Based on Pentathiophene Donor and Alkylated Indacenodithiophene-Based Acceptors with Efficiency over 8\% ACS Appl. Energy Mater. 1 (2018) 2150-2156.

[4] Y. Huo, H.-L. Zhang, X. Zhan, Nonfullerene All-Small-Molecule Organic Solar Cells, ACS Energy Lett. 4 (2019) $1241-1250$ 
[5] A.K.K. Kyaw, D.H. Wang, D. Wynands, J. Zhang, T.-Q. Nguyen, G.C. Bazan, A.J. Heeger, Improved light harvesting and improved efficiency by insertion of an optical spacer $(\mathrm{ZnO})$ in solution-processed small-molecule solar cells, Nano Lett. 13 (2013) 3796-3801.

[6] T.S. van der Poll, J.A. Love, T.-Q. Nguyen, G.C. Bazan, Non-basic high-performance molecules for solutionprocessed organic solar cells, Adv. Mater. 24 (2012) 3646-3649.

[7] S. Sergeyev, W. Pisulab, Y.H. Geerts, Discotic liquid crystals: a new generation of organic semiconductors, Chem. Soc. Rev. 36 (2007) 1902-1929.

[8] Y. Miyake, Y. Shiraiwa, K. Okada, H. Monobe, T. Hori, N. Yamasaki, H. Yoshida, M.J. Cook, A. Fujii, M. Ozaki, Y. Shimizu, High carrier mobility up to $1.4 \mathrm{~cm}^{2} \mathrm{~V}^{-1} \mathrm{~s}^{-1}$ in non-peripheral phthalocyanine, Appl. Phys. Express 4 , (2011) 021604-1-021604-3.

[9] Z. An, J. Yu, S.C. Jones, S. Barlow, S. Yoo, B. Domercq, P. Prins, L.D.A. Siebbeles, B. Kippelen, High electron mobility in room-temperature discotic liquid-crystalline perylene diimides, S. R. Marder, Adv. Mater. 17 (2005) 2580-2583.

[10] Q.-D. Dao, T. Hori, T. Masuda, K. Fukumura, T. Kamikado, F. Nekelson, A. Fujii, Y. Shimizu, M. Ozaki Mechanism of Degradation and Improvement of Stability on Mesogenic-Phthalocyanine-Based Bulk Heterojunction Solar Cell, Jpn. J. Appl. Phys. 52 (2013) 012301-1-012301-5.

[11] Q.-D. Dao, T. Hori, K. Fukumura, T. Masuda, T. Kamikado, A. Fujii, Y. Shimizu, M. Ozaki, Efficiency enhancement in mesogenic-phthalocyanine-based solar cells with processing additives, Appl. Phys. Lett. 101 (2012) 263301-1-263301-4.

[12] Q.-D. Dao, A. Fujii, M. Ozaki, Fabrication of tandem solar cells with all-solution processed multilayer structure using non-peripherally substituted octahexyl tetrabenzotriazaporphyrins, Jpn. J. Appl. Phys. 55 (2016) 03DB01-103DB01-6.

[13] Q.-D. Dao, T. Uno, M. Ohmori, K. Watanabe, H. Itani, A. Fujii, Y. Shimizu, M. Ozaki, Effects of thermal-annealing and processing-additive treatment on crystallization-induced phase separation in organic solar cells utilizing octapentyl tetrabenzotriazaporphyrins, J. Phys. D: Appl. Phys. 48 (2015) 385103-1-385103-5.

[14] Q.-D. Dao, T. Hori, K. Fukumura, T. Masuda, T. Kamikado, A. Fujii, Y. Shimizu, M. Ozaki, Effects of processing additives on nanoscale phase separation, crystallization and photovoltaic performance of solar cells based on mesogenic phthalocyanine, Org. Electron. 14 (2013) 2628-2634.

[15] J.C. Swarts, E.H.G. Langner, N. Krokeide-Hove, M.J. Cook, Synthesis and electrochemical characterisation of some long chain 1,4,8,11,15,18,22,25-octa-alkylated metal-free and zinc phthalocyanines possessing discotic liquid crystalline properties, J. Mater. Chem.11 (2001) 434-443.

[16] S.M. Critchley, M.R. Willis, M.J. Cook, J. McMurdo, Y. Maruyama, Deposition of Ordered Phthalocyanine Films by Spin Coating, J. Mater. chem., 2(2) (1992) 157-159.

[17] J. Mack, M.J. Stillman, N. Kobayashi, Application of MCD spectroscopy to porphyrinoids, Coordination Chemistry Reviews 251 (2007) 429-453.

[18] S. Morita, A.A. Zakhidov, K. Yoshino, Doping effect of buckminsterfullerence in conducting polymer: change of absorption spectrum and quenching of luminescence, Solid State Commun. 82 (1992) 249-252.

[19] N.S. Sariciftci, L. Smilowitz, A.J. Heeger, F. Wudl, Photoinduced Electron Transfer from a Conducting Polymer to Buckminsterfullerene, Science 258 (1992) 1474-1476.

[20] K. Yoshino, X.H. Yin, S. Morita, T. Kawai, A.A. Zakhidov, Enhanced photoconductivity of C60 doped poly(3alkylthiophene), Solid State Commun. 85 (1993) 85-88. 